\title{
Serum Magnesium Levels in Healthy Pregnant and Pre-Eclamptic Patients -A Cross-Section Study
}

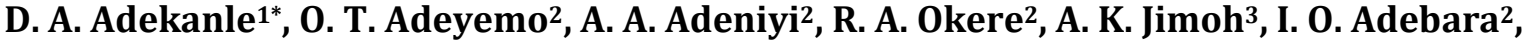 \\ A. Bakare ${ }^{2}$, A. S. Atiba ${ }^{3}$, A. Adelekan ${ }^{3}$, B. A. Olofinbiyi ${ }^{4}$ \\ ${ }^{1}$ Department of Obstetrics \& Gynaecology, Faculty of Clinical Sciences, College of Health Sciences, Ladoke \\ Akintola University of Technology, Osogbo, Nigeria \\ ${ }^{2}$ Department of Obstetrics \& Gynaecology, Federal Medical Centre, Ido-Ekiti, Nigeria \\ ${ }^{3}$ Department of Chemical Pathology, Federal Medical Centre, Ido Ekiti, Nigeria \\ ${ }^{4}$ Department of Obstetrics \& Gynaecology, Ekiti State University Teaching Hospital, Ado Ekiti, Nigeria \\ Email: ${ }^{*}$ adekanle2000@yahoo.co.uk
}

Received 12 April 2014; revised 9 May 2014; accepted 5 June 2014

Copyright (C) 2014 by authors and Scientific Research Publishing Inc.

This work is licensed under the Creative Commons Attribution International License (CC BY).

http://creativecommons.org/licenses/by/4.0/

(c) (i) Open Access

\section{Abstract}

Background: Pre-eclampsia complicates $2 \%$ - $8 \%$ of pregnancies. Various efforts have been put forward for its prevention and treatment. Magnesium sulphate is presently the recommended drug for the prevention and treatment of eclampsia and severe pre-eclampsia. Objectives: The study aimed to compare the serum magnesium in a healthy pregnant women and pre-eclamptic women. It determined demographic characteristic of the study population and recommended the prophylactic usage of magnesium sulphate in pregnancy in our environment. Method: This was a prospective case control study comparing the serum magnesium levels in pre-eclampsia and normal pregnancy tertiary hospitals. The women who satisfied the inclusion criteria were recruited in the two groups (seventy five in the healthy pregnant women and seventy five in the pre-eclamptic women). The blood samples were collected and analysed for the serum magnesium and urine sample for urinalysis. Result: Total of 150 patients comprises 75 normal pregnant women and 75 cases of pre-eclampsia. The mean serum magnesium in the normal pregnant women was $0.73( \pm 0.14) \mathrm{mmol} / \mathrm{L}$ while in preeclampsia the level was $0.58( \pm 0.17) \mathrm{mmol} / \mathrm{L}$. This is statistically significant $(t=6.120, p=0.000)$. There was significance difference in the mean age of patients with pre-eclampsia and normal pregnancy. The mean parity in the pre-eclampsia was 0.80 and in the normal pregnancy was 1.4 and was statistically significant $(t=3.40$, $p$ value $<0.001)$. The mean gestational age of the pre-eclamptic was 36.5 weeks while it was 28.7 weeks in the normal pregnant women $(t=10.80, p=0.000)$. Conclusion: The findings in this research work revealed that

"Corresponding author.

How to cite this paper: Adekanle, D.A., Adeyemo, O.T., Adeniyi, A.A., Okere, R.A., Jimoh, A.K., Adebara, I.O., Bakare, A., Atiba, A.S., Adelekan, A. and Olofinbiyi, B.A. (2014) Serum Magnesium Levels in Healthy Pregnant and Pre-Eclamptic Patients-A Cross-Section Study. Open Journal of Obstetrics and Gynecology, 4, 561-568.

http://dx.doi.org/10.4236/ojog.2014.49080 
the pre-eclamptic women have lower serum magnesium level compared to the normal pregnant women, and it may therefore be interesting to do a larger multicenter study with possibility of developing a marker for this disease of theories.

\section{Keywords}

Pre-Eclampsia, Eclampsia, Serum Magnesium, Marker and Prophylaxis

\section{Introduction}

Pre-eclampsia is an unpredictable, multi-organ disorder unique to human pregnancy. It is associated with a significant maternal and fetal morbidity and mortality worldwide [1]-[3]. Despite a steady reduction in maternal mortality from this disorder in more developed countries, it remains as one of the most common reasons for the death of a woman during pregnancy especially in developing countries [1]. Prevention of this condition has been disappointing [4] while treatment remains as a challenge. The mainstay of the management remains as integrated antenatal care, access to monitoring services, stabilization of the maternal condition and delivery of the baby through the safest and fastest route to the benefit of both the mother and child [1] [4].

Magnesium deficiency has been implicated as a possible cause of pre-eclampsia [5]-[7]. Pregnancy imposes a great stress on the nutritional reserves, with associated depletion of essential nutrients like iron, folic and, vitamin B complexes, vitamin A, calcium and magnesium, protein and energy [7] [8]. At the moment, evidence to support routine magnesium supplementation for all pregnant women has not been substantiated, though most studies have reported reduced magnesium levels in pregnancy and worse levels in pre-eclampsia [5]-[7] [9]. While most researches comparing magnesium levels in normal and pre-eclamptic pregnancy have occurred in developed nation, there has been a paucity of literature in the developing nations where most of the maternal deaths from pre-eclampsia occur [1] [10] [11]. Magnesium is a critical physiological ion and its deficiency might contribute to the development of pre-eclampsia, to impaired neonatal development and to metabolic problems extending into adult life.

It is therefore necessary to undertake a research to identify women who will benefit from magnesium supplementation. The identification of low serum magnesium as a risk factor for developing pre-eclampsia will help in developing intervention strategies that will reduce the incidence and complications of pre-eclampsia especially in the developing countries. The objective of our study is to compare serum levels of pre-eclamptic patients with healthy patients and sociodemographic characteristics of the study groups.

\section{Methodology}

\subsection{Study Design}

This was a prospective case control study comparing the serum magnesium level in pre-eclamptic patient and healthy pregnant women in Ekiti over six months period (between February, 2012 and July 2012).

\subsection{Study Location}

The study was carried out in the Department of Obstetrics and Gynaecology at the Federal Medical Centre Ido-Ekiti and Ekiti State University Teaching Hospital Ado-Ekiti. These hospitals serve as a referral centre for primary and secondary health care centres in Ekiti, Ondo, Kogi and Kwara States of Nigeria.

\subsection{Study Population}

Subjects for this study were from the population of healthy pregnant women and pre-eclamptic women receiving care in the study location that satisfied the inclusion criteria such as all pregnant women greater than 20 to 42 weeks pregnant attending antenatal clinic, booking clinic or emergency room diagnosed to have preeclampsia at study location with written informed consent obtained. They are black race. Exclusion criteria were patient with medical complications such as essential hypertension, renal disorders and cardiovascular disorder, patients who 
have medical complication with superimposed pre-eclampsia, patients with molar pregnancy and feature of pre-eclampsia and patients presently on treatment for pre-eclampsia using magnesium.

Pre-eclampsia is defined as the occurrence of hypertension in combination with proteinuria, developing after 20 weeks gestation in a previously normotensive, non-proteinuria patient [12]. The diagnosis of hypertension in pregnancy is made by either one measurement of diastolic blood pressure equal to or greater than $110 \mathrm{mmHg}$ or two consecutive measurement of diastolic blood pressure equal to or greater $90 \mathrm{mmHg} 4$ or more hours' apart [12]. Korokoff phase V was used as a measure of diastolic pressure. Significant proteinuria is defined as, one 24 hour collection with a total protein excretion of $300 \mathrm{mg}$ or more or two random clean-catch or catheter specimen urine specimens with $2+(1 \mathrm{~g}$ albumin/Litre $)$ or more on reagent strip or $1+(0.3 \mathrm{~g}$ albumin/Litre $)$ if specific gravity less than 1.030 or $\mathrm{pH}$ is less than 8 [12].

\section{Measurement of Serum Magnesium Concentration}

Serum magnesium has been measured by various techniques including fluorometry, flame emission, spectroscopy and atomic absorption spectrometry (AAS). Simple, direct and automation ready procedure for measuring magnesium concentration in biological samples are becoming popular.

Bioassay systems' magnesium assay kit is designed to measure magnesium directly in biological samples without any pretreatment. A calmagite dye in the kit forms a coloured complex specifically with magnesium. The intensity of the colour, measured at $520 \mathrm{~nm}$ is directly proportional to the magnesium concentration in the sample.

About five millilitres of blood was collected into a plain non-anticoagulated bottle. This was allowed to clot for thirty minutes and the serum harvested after centrifuging at $3000 \mathrm{~g}$ for 10 minutes and stored in a deep freezer until analysis.

The assay was done using a commercially manufactured ready to use kit by Agappe Diagnostics Switzerland GmbH, Langackerstrasse 29-6330 2 Cham-Switzerland.

\section{Urinalysis}

A clean catch urine specimen of about five millilitres was collected into a plain universal bottle then immediately assessed for significant proteinuria, $\mathrm{pH}$ and specific gravity. A urine dipstick manufactured by Atlas Medical, William James House, Cowley Road, CB4 0WX, UK.

\section{Analysis of Data}

All the results were recorded in a proforma. The data and information obtained from the study was processed using statistical package for social science (SPSS) computer software version 17, frequency tables were made and results tested for statistical significance using the student t-test and chi-square test. The significant value is put at $\mathrm{p}<0.05$.

\section{Ethical Clearance}

Ethical Clearance for this study has been obtained from the ethical review board of the hospital.

\section{Results}

The study evaluated seventy-five normal pregnant women and seventy-five with pre-eclampsia had their serum magnesium estimated; totaling one hundred and fifty pregnant women.

The mean age for the pre-eclamptic was $28.52 \pm 4.82$ years range 18 - 40 years while the mean age for normal pregnant women was $31.00 \pm 4.12$ years with range of 18 - 40 years.

The mean systolic blood pressure in the pre-eclamptic was $157.1 \pm 11.9 \mathrm{mmHg}$ with range of $130-190$ $\mathrm{mmHg}$ while the mean diastolic blood pressure was $100.7 \pm 8.4 \mathrm{mmHg}$ with range of 90 - $130 \mathrm{mmHg}$; and mean proteinuria on dipstick was $2.5 \pm 0.6$, with range of 2 - 4 .

The majority of the women $62(41.3 \%)$ were within age 30 - 34 years, while $42.7 \%$ were teenagers.

Eighty-two (54.7\%) were skilled workers while 14 (9.3\%) were in school.

Majority 62 (341.3\%) had tertiary education while 9 (6.0\%) had only primary education. One hundred and 
forty six (97.3\%) were married while 3 (2.0\%) were single.

Majority of the patient evaluated 131 (87.3\%) were Christians while 19 (12.7\%) were Muslims.

The serum magnesium sulphate value in the pre-eclamptic was $0.30-1.00 \mathrm{mmol} / \mathrm{Litre}$ with a mean value 0.58 $\pm 0.17 \mathrm{mmol} / \mathrm{L}$ while the value for normal pregnancy has a range of $0.40-1.10 \mathrm{mmol} / \mathrm{L}$ and a mean value of $0.73 \pm 0.13 \mathrm{mmol} / \mathrm{L}$. This is statistically significant $(\mathrm{t}=6.120, \mathrm{p}=0.000)$.

The mean age of the cases was $28.52( \pm 4.90)$ years while that of the control was $31.0( \pm 4.11)$, there was statistically significant difference $(\mathrm{t}=2.87, \mathrm{p}=0.005)$.

The mean parity of the cases was 0.800 that of the control was $1.4(t=3.40 ; p=0.001)$, which was statistically significant.

The mean gravidity in cases was 2.55 while that of the control was $3.04(t=2.75, p=0.007)$ statistically significant.

Table 1, Table 2 and Figure 1 represent the gestational age at presentation of cases and control. It shows that most of the cases (pre-eclamptic) presented at late gestation-above 35 weeks.

\section{Discussion}

Preeclampsia/eclampsia still remains as one of the major causes of maternal and perinatal morbidity and mortality worldwide especially developing countries including Nigeria [1]-[3]. In spite of intensive research, the precise cause of pre-eclampsia is not known with certainty. The pathogenesis of placenta dysfunction, the initiation of systemic vasospasm, ischaemia and thrombosis that eventually lead to morbidity or mortality in the mother and/or fetus are poorly understood [1] [4].

More awareness and enabling factors should be created for more women to access antenatal facilities. Early recognition of women at risk of pre-eclampsia will enable the identification of high risk women who may benefit from enhanced surveillance and prophylaxis.

Table 1. Socio-demographic characteristics of the respondents.

\begin{tabular}{|c|c|c|}
\hline Variable & Number & Percentage \\
\hline \multicolumn{3}{|l|}{ Age (years) } \\
\hline$\leq 19$ & 14 & 2.7 \\
\hline $20-24$ & 10 & 6.7 \\
\hline $25-29$ & 50 & 33.3 \\
\hline $30-34$ & 62 & 41.3 \\
\hline$\geq 35$ & 24 & 16.0 \\
\hline \multicolumn{3}{|l|}{ Education } \\
\hline Primary/Arabic & 9 & 6.0 \\
\hline Secondary & 30 & 20.0 \\
\hline Teacher training college & 49 & 32.7 \\
\hline Polytechnic/University & 62 & 41.3 \\
\hline \multicolumn{3}{|l|}{ Marital status } \\
\hline Single & 3 & 2.0 \\
\hline Married & 146 & 97.3 \\
\hline Widowed & 1 & 0.7 \\
\hline \multicolumn{3}{|l|}{ Religion } \\
\hline Christian & 131 & 87.3 \\
\hline Islam & 19 & 12.7 \\
\hline
\end{tabular}


Table 2. Socio-demographic characteristics and serum magnesium sulphate of cases and control-comparative analysis.

\begin{tabular}{ccccc}
\hline Variable & Case $(\mathrm{N}=75)$ & Control $(\mathrm{N}=75)$ & t-test & p-value \\
\hline Serum magnesium (mmol/L) & $0.5779( \pm 0.1658)$ & $0.7296( \pm 0.1364)$ & 6.120 & 0.000 \\
Age (years) & $28.52( \pm 4.82)$ & $31.00( \pm 4.11)$ & 3.39 & 0.001 \\
Parity & 0.800 & 1.40 & 3.40 & 0.001 \\
Gravidity & 2.400 & 3.04 & 2.25 & 0.007 \\
No of abortions & 0.56 & 0.60 & 0.00 & 1.00 \\
No of children alive & 0.86 & 1.39 & 10.80 & 0.014 \\
Gestational age at presentation (weeks) & 36.5 & 28.7 & 0.00 \\
\hline
\end{tabular}

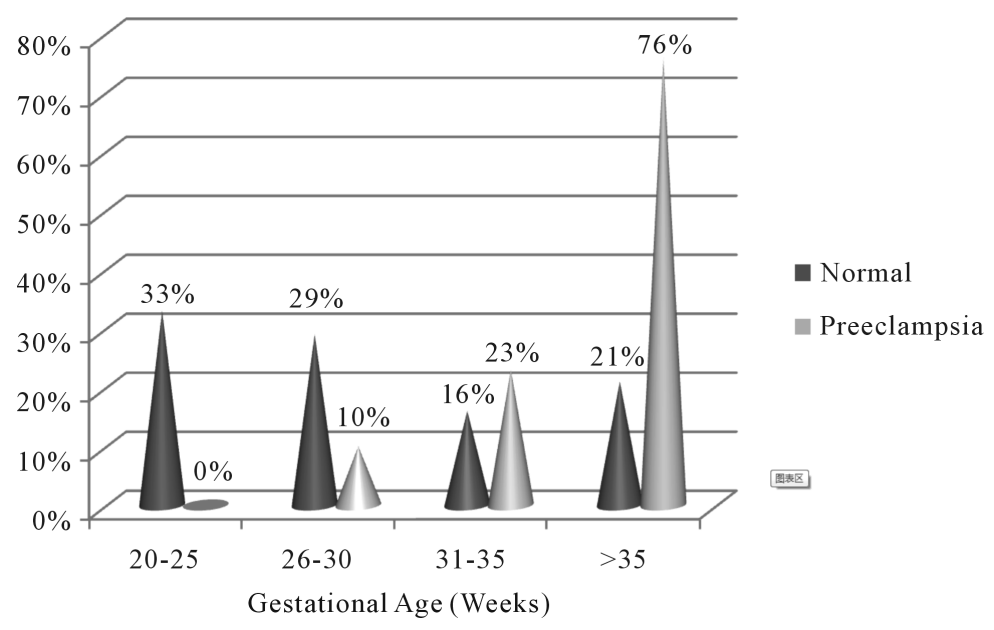

Figure 1. Gestational age with proportion of pre-eclamptic and normal pregnancy.

In this study the mean age for the cases was $28.62( \pm 4.82)$ years while the mean age for the normal pregnant women was $31.0( \pm 4.12)$ years, this is similar to other studies [13] [14].

Nulliparity is widely considered to be a hallmark of pre-eclampsia [15], this study has shown a significant lower parity among the pre-eclampstic compared to normal pregnant women. It is interesting to note that those developing severe pre-eclampsia at early gestation age are at risk for having the condition repeat in subsequent pregnancies.

The mean gestational age at presentation for the pre-eclampsia was 36.5 weeks and most presented at gestational age of 35 weeks and above. This conform to the widely held observation of tertiary institution being a referral centre where majority of unbooked complicated pregnancies are managed, hence the advance gestational age at presentation, consistent with findings in other studies [14].

In this study the serum magnesium level of the control normal pregnant patient was $0.40-1.10 \mathrm{mmol} / \mathrm{L}$ (mean was $0.73 \mathrm{mmol} / \mathrm{L}$ ) while that of pre-eclamptic women range was $0.30-1.00 \mathrm{mmol} / \mathrm{L}$ with mean value of $0.58 \mathrm{mmol} / \mathrm{L}$ this is similar to findings in other studies [14] [16]. The level of serum magnesium are affected by dietary habits, physiological/pathological state, and method of estimation used. In our environment diet rich in magnesium include rice, cassava, beans soya beans, beef, vegetable and yam flour [17] [18].

The health seeking behavior of our women is generally poor in the developing countries which permit the adverse effects of the various levels of delays. In this study the booking status of the patient revealed that the unbooked patients with pre-eclampsia was 42 (97.7\%) compared with booked patient 33 (30.3\%). This similar with findings from other studies [19] [20] where most of complications of pregnancy are found. Previous history of pre-eclampsia has been known in literature as a risk factor for repeat pre-eclampsia [21] [22] in spite of the said immunological adjustment expected. In a review of proportion based studies, Harskamp and Zeeman noted 
a relationship between pre-eclampsia and increased risk of later chronic hypertension. In our study it was noted that a high proportion of the women with previous history of pre-eclampsia had pre-eclampsia compared with women with no history of pre-eclampsia this is similar to finding in other research work [11] [21].

The major finding in this study is that of significant lower level of serum magnesium in pre-eclampsia patients $(0.58 \pm 0.17 \mathrm{mmol} / \mathrm{L})$ compared to normal pregnancies $(0.73 \pm 0.14 \mathrm{mmol} / \mathrm{L})$; this observation is similar with finding in other studies [13] [14] [16].

The aetiology of reduced levels of serum magnesium is not known. It is uncertain whether how serum magnesium result in pre-eclampsia or that pre-eclampsia in various parts of the world have shown diverse conclusion [23]-[26].

Adams and coworkers reported that low cellular magnesium levels in women with pre-eclampsia and may contribute to the development of hypertension in this group of patients.

Also studies have shown decrease in serum magnesium levels has been considered as the cause of pathogenesis of pre-eclampsia. Also the success of magnesium therapy as a treatment for eclamptic seizures and the known effect of magnesium on vascular response in-vitro suggested that magnesium might be deficient in women with pre-eclampsia [26]. This hypothesis was supported by the observation of reduced magnesium concentration in serum, intracellularly and in erythroacyte membrane. Tranquilli and other co-worker postulated that platelet functionality alterations have been correlated to the onset of hypertension in pregnancy and oral magnesium supplementation has been found to counteract such alterations. They tested the effect of 4 weeks of supplementation of oral magnesium protolidone $360 \mathrm{mg} / \mathrm{day}$ on 48 women 28 pre-eclampsia and 20 controls.

Oral magnesium supplementation significantly increased platelet fluorescence in both normotensive and pre-eclamptic women. In normotensive patients, it significantly increases the activity of $\mathrm{Na}^{+} / \mathrm{k}^{+}$-ATPase, $\mathrm{Ca}^{2+}$ ATPase and reduced intraplatelet free calcium. In pre-eclamptic magnesium supplementation increase $\mathrm{Na}^{+} / \mathrm{k}^{+}-$ ATPase activity and decreases intracellular calcium ions, this in turn contributes to reducing the activity of $\mathrm{Ca}^{2+}$ ATPase. The authors concluded that magnesium supplementation in preventing preeclampsia seem to have a consistent biochemical and clinical background.

However contrary view to the significance of using magnesium supplementation in pregnancy to prevent preeclampsia have been stressed in various studies and guidelines [6] [21] [27]. WHO (2010) in its recent recommendations for prevention and treatment of pre-eclampsia and eclampsia submitted that magnesium supplementation is not recommended for prevention of pre-eclampsia but prevention of eclampsia in women with severe pre-eclampsia in preference to other anticonvulsants [28].

Pre-eclampsia has been termed disease of theories as no exact cause has been found. There is at the moment no full proof reliable marker. The findings in this study revealed a low level of serum magnesium in pre-eclampsia is more than coincidental relationship and that magnesium may in fact be a marker for pre-eclampsia. This assertion may require a wide multicentre research work over reasonable duration. The possibility that magnesium supplementation may not be out of place.

Other research that may be important is to estimate the serum magnesium in a large cohort of pregnant women before 20 weeks gestational age and correlate results obtained with subsequent development of pre-eclampsia.

In Nigeria where maternal morbidity and mortality is highly unacceptable, for which pre-eclampsia is a major contributor, research into the identification of an early marker of this disease, with varied and uncertain aetiology, is of utmost importance.

Magnesium deficiency may contribute towards placenta insufficiency and thus to the development of pre-eclampsia as it contribute towards uterine artery spasm, fetal growth retardation and has essential regulatory role in prostaglandin synthesis [11] [28]-[30]. It has been suggested that magnesium supplementation during pregnancy can reduce maternal morbidity and improve fetal outcome.

\section{Conclusion}

This study showed that there is a significantly lower level of magnesium in the pre-eclamptic pregnant women compared to the normotensive pregnant women as stated in the study hypothesis. In the light of the above considerations coupled with the fact that prevention of preeclampsia could mean a major breakthrough in prenatal care of pregnant women, it is pertinent that we must start to re-address the issue of magnesium and preeclampsia 
more critically.

\section{References}

[1] Duley, L. (2009) The Global Impact of Preeclampsia and Eclampsia. Seminars in Perinatology, 33, 130-137. http://dx.doi.org/10.1053/j.semperi.2009.02.010

[2] Steegers, E.A., Von Dadelszen, P., Duvelcott, J.J. and Pijnenborg, R. (2010) Pre-Eclampsia. Lancet, 376, 631-644. http://dx.doi.org/10.1016/S0140-6736(10)60279-6

[3] Centre for Maternal and Child Enquiries (CMACE) (2011) Saving Mothers' Lives: Reviewing Maternal Deaths to Make Motherhood Safer: 2006-08. The Eighth Report on Confidential Enquiries into Maternal Deaths in the United Kingdom. BJOG, 118, 68-72.

[4] Urato, A.C. and Norwitz, E.R. (2011) A Guide towards Pregnancy Management of Detective Implatic and Placentation. Best Practice and Research Clinical Obstetrics and Gynaecology, 25, 367-387. http://dx.doi.org/10.1016/j.bpobgyn.2011.01.003

[5] Roberts, J.M., Myatt, L., Spon, C.Y., et al. (2010) Vitamins C and E to Prevent Complications of Pregnancy Associated Hypertension. New England Journal of Medicine, 362, 1282-1291. http://dx.doi.org/10.1056/NEJMoa0908056

[6] Nygaard, I.H., Valbo, A., Pethick, S.V. and Bohmer, T. (2008) Does Oral Magnesium Substitution Relieve Pregnancy-Induced Leg Cramps? European Journal of Obstetrics \& Gynecology and Reproductive Biology, 141, 23-26. http://dx.doi.org/10.1016/j.ejogrb.2008.07.005

[7] Catov, J.M., Nohr, E.A., Bodnar, L.M., Knudson, V.K., Olsen, S.F. and Olsen, J. (2009) Association of Preconceptional Multivitamin Use with Reduced Risk of Preeclampsia among Normal-Weight Women in the Danish National Birth Cohort. American Journal of Epidemiology, 169, 1304-1311. http://dx.doi.org/10.1093/aje/kwp052

[8] Hofmeyr, G.J., Duley, L. and Atallah, A. (2007) Dietary Calcium Supplementation for Prevention of Preeclampsia and Related Problems: A Systematic Review and Commentary. BJOG, 114, 933-943. http://dx.doi.org/10.1111/j.1471-0528.2007.01389.x

[9] Harrison, V., Fawcus, S. and Jordan, E. (2007) Magnesium Supplementation and Perinatal Hypoxia: Outcome of a Parallel Group Randomized Trial in Pregnancy. BJOG, 114, 994-1002. http://dx.doi.org/10.1111/j.1471-0528.2007.01409.x

[10] Shennah, A. (2007) Hypertension in Pregnancy. In: Dewhurst Textbook of Obstetrics and Gynaecology for Postgraduates, 7th Edition, Blackwell Sciences Ltd., Hoboken, 227-235.

[11] Cunningham, F.G., Veno, K.J. and Bloom, S.L. (2010) Pregnancy Hypertension. In: Williams Obstetrics, 23rd Edition, McGraw-Hill Professional, New York, 706-755.

[12] Golomohammed Iou, S., Amirabi, A., Yazdian, N. and Pashapour, N. (2008) Evaluation of Serum Calcium, Magnesium, Copper and Zinc Levels in Women with Preeclampsia. International Journal of Medical Sciences, 33, 231-234.

[13] Igberase, G.O., Ebeigbe, P.N., Okonta, P.I., Okpere, E.E. and Gharoro, E.P. (2007) Serum Magnesium Levels in Normal and Pre-Eclampsia Pregnancy in Benin City. Nigeria Medical Journal, 48, 21-23.

[14] North, R.A., McCowan, L.M., Dekker, G.A., Poston, L., Chan, E.H.Y., Stewart, A.W., Black, M.A., Taylor, R.S., Walker, J.J., Baker, P.N. and Kenny, L.C. (2011) Clinical Risk Prediction for Pre-Eclampsia in Nulliparous Women: Development of Model in International Prospective Cohort. BMJ, 342, d1875.

[15] Odigie, I.P., Anorlu, R.I., Adesiyun, A.E. and Odum, C.U. (2004) Serum Magnesium Levels in Non-Pregnant, Pregnant and Pre-Eclamptic Women in Lagos, Nigeria. Nigerian Quarterly Journal of Hospital Medicine, 14, 178-180.

[16] Redman, C.W.G. (2008) Sergent II: Circulating Microparticles in Normal Pregnancy and Preeclampsia. Placenta, 22, 573.

[17] Swaminathan, R. (2003) Magnesium Metabolism and Its Disorder. Archive of the Clinical Biochemist Reviews, 24, 4766.

[18] Fabamwo, A.O., Akinola, D.I. and Mojoyinola, O.O. (2010) The Tragic Consequences of Unsupervised Pregnancies among Patients Referred to a Tertiary Maternity Unit in Lagos, South West Nigeria. The Internet Journal of Tropical Medicine, 7, 9. http://dx.doi.org/10.5580/23d1

[19] Tucker, A., Ogutu, D., Yoong, W., Nauta, M. and Fakokunde, A. (2009) The Unbooked Mother: A Cohort Study of Maternal and Foetal Outcome in a North London Hospital. Archives of Gynecology and Obstetrics, 281, 613-616.

[20] National Collaborating Centre for Women's and Children's Health (2010) NICE Clinical Guideline 107. Hypertension in Pregnancy: The Management of Hypertensive Disorder during Pregnancy.

[21] Hernandez-Diaz, S., Toh, S. and Cnattingius, S. (2009) Risk of Pre-Eclampsia in First and Subsequent Pregnancies: Prospective Cohort Study. BMJ, 338, b2255. http://dx.doi.org/10.1136/bmj.b2255 
[22] Makinde, O.N., Adegoke, O.A., Adeniran, I.A., Ndububa, D.A., Adeyemi, A.B., Owolabi, A.T., Kuti, O. and Orji, E.O. (2009) Salawu HELP Syndrome: The Experience at Ile-Ife. Nigeria Journal of Obstetrics and Gynaecology, 29, 195199.

[23] Li, S. and Tian, H. (1997) Oral Low Dose Magnesium Gluconate Preventing Pregnancy Induced Hypertension. Chang Hua Fu Chan Ko Tsa Chih, 32, 613-615.

[24] Rudnicki, M., Frolich, A., Rasmussen, W.F. and McNair, P. (1991) The Effect of Magnesium on Maternal Blood Pressure in Pregnancy Induced Hypertension. A Ramdomized Double-Blind Placebo Controlled Trial. Acta Obstetricia et Gynecologica Scandinavica, 80, 445-450. http://dx.doi.org/10.3109/00016349109007158

[25] Altura, B.M. and Altura, B.T. (1981) Magnesium Ions and Contraction of Vascular Diseases. Federation Proceedings, 40, 2672-2679.

[26] Hofmeyer, G.J., Lawrie, T.A., Atallah, A.N. and Dulley, L. (2010) Calcium Supplementation during Pregnancy for Pre- venting Hypertensive Disorders and Related Problems. Cochrane Database of Systematic Review, CD001059

[27] WHO (2010) WHO Handbook for Guideline Development. World Health Organisation, Geneva.

[28] Khong, Y. and Brosens, I. (2011) Defective Deep Placentation. Best Practice \& Research Clinical Obstetrics \& Gynaecology, 25, 301-311. http://dx.doi.org/10.1016/j.bpobgyn.2010.10.012

[29] Tjoa, M.I., Levine, R.J. and Karumaachi, S.A. (2007) Angiogenic Factors and Preeclampsia. Front Brosai, 12, 23952402

[30] Conradt, A., Weidinger, H. and Algayer, G. (1985) Magnesium Deficiency, a Possible Cause of Pre-Eclampsia: Reduction of Frequency of Premature Rupture of Membranes and Premature or Small for Date Deliveries after Magnesium Supplementation. Journal of the American College of Nutrition, 4, 321. 